\title{
Fibrosarcoma of the Lower Eyelid in a Dog
}

\author{
I-Hsuan Teng', Ming-Wei Lee ${ }^{2}$, Chun-Fu Lin ${ }^{1}$, Geng-Ruei Chang1* \\ ${ }^{1 *}$ Department of Veterinary Medicine, National Chiayi University, 580 Xinmin Road, Chiayi, Taiwan, 60054, ROC \\ ${ }^{2}$ Veterinary Teaching Hospital, College of Veterinary Medicine, National Chiayi University, 580 Xinmin Road, Chiayi, Taiwan, 60054, ROC
}

*Correspondence to: Department of Veterinary Medicine, National Chiayi University, 580 Xinmin Road, Chiayi, Taiwan, 60054, ROC; Tel.: 886-5-2732946; Fax: 8865-2732717; E-mail: grchang@mail.ncyu.edu.tw

Received: September 04, 2017; Accepted: September 19, 2017; Published: September 25, 2017;

\begin{abstract}
A ten-year-old neutered male golden retriever weighing $39.2 \mathrm{~kg}$ was presented with a lump and considerable discharge around the right eye. Clinical examination revealed a firm, smooth, touch-sensitive mass on the right lower eyelid. Laboratory examination, including clinical haematology and chemistry revealed no significant abnormalities. After the mass was removed through surgery, gross findings showed that the mass was pink, cauliflowerlike, and hairless. Histopathological studies revealed a characteristic pattern of well-demarcated and nonencapsulated lesions. The neoplastic cells in the mass were markedly spindle-shaped and infiltrated basophilic intermediate cells in interwoven or herringbone patterns. On the basis of these findings, the dog was diagnosed with fibrosarcoma. On the basis of the American Joint Committee on Cancer staging system, the fibrosarcoma was classified as histologic grade I-II (T1aNOM0). It should be frequently monitored for local recurrence, and recurrence of the tumour should be properly treated.
\end{abstract}

Keywords: fibrosarcoma, lower eyelid, dog

\section{Introduction}

Soft tissue sarcomas (STSs) such as fibrosarcoma, liposarcoma, lymphoma, hemangiosarcoma, and peripheral nerve sheath tumours are occasionally seen in dogs and cats [1-6]. They are mesenchymal neoplasms derived from soft connective tissues, which can occur in at any anatomical site of the body, most commonly involving cutaneous and subcutaneous tissues [5]. STSs have been reported to comprise $15 \%$ of all canine skin tumours [6-19], and most of them are solitary tumours in middle-aged to older dogs. No specific breed or sex has a predilection for STSs [12].

Fibrosarcomas of the skin, subcutaneous tissue, or oral cavity are general malignant [2]. Histologically, they can be well circumscribed but unencapsulated. They can be comprised of mature fibrocyte, which produce abundant collagen. Well-differentiated spindle-shaped tumour cells are arranged in interwoven or herringbone patterns. Cytoplasm is scant, and nuclei are fairly uniform, with inconspicuous, elongated to oval-shaped nucleoli. Malignant characteristics include packed spindle-shaped fibroblasts exhibiting active mitotic figures and marked cellular pleomorphism with increasing cellular density [16]. These characteristics must be distinguished from peripheral nerve sheath tumours (PNSTs) and leiomyosarcomas. PNSTs are composed of interwoven or herringbone Schwann cells, which pronounce collagenous stroma $[5,10]$. Leiomyosarcoma is also composed of spindle cells, but it contains abundant deeply eosinophilic cytoplasm and exhibits some vacuole [17].

\section{Case history}

A ten-year-old neutered male golden retriever weighing 39.2 $\mathrm{kg}$ was presented. Three weeks previously, the owner had noticed a mass on the dog's right lower eyelid, which produced considerable discharge in the eye. The mass rapidly doubled in size. The dog was in good general condition. Physical examination, panting respiratory rate, and other items revealed no serious abnormalities. The results of laboratory examination, including clinical haematology (Table 1) and chemistry (Table 2), faecal floatation, and thoracic radiography revealed no serious clinical abnormalities.

Table 1: Complete blood count

\begin{tabular}{|l|l|l|l|}
\hline Test a & Unit & Result & Reference Interval $^{\mathbf{b}}$ \\
\hline RBC & $10^{6} / \mu \mathrm{L}$ & 6.77 & $5.65-8.87$ \\
\hline HCT & $\%$ & 44.3 & $37.3-61.7$ \\
\hline HGB & $\mathrm{g} / \mathrm{dL}$ & 15.1 & $13.1-20.5$ \\
\hline MCV & $\mathrm{fL}$ & 65.4 & $61.6-73.5$ \\
\hline MCH & $\mathrm{Pg}$ & 22.3 & $21.2-25.9$ \\
\hline MCHC & $\mathrm{g} / \mathrm{dL}$ & 34.1 & $32.0-37.9$ \\
\hline WBC & $10^{3} / \mu \mathrm{L}$ & $\mathbf{2 7 . 1 9} \uparrow$ & $5.05-16.75$ \\
\hline Neu. & $(\%) 10^{3} / \mu \mathrm{L}$ & $\mathbf{1 6 . 9 6} \uparrow$ & $2.95-11.64$ \\
\hline Eosino. & $(\%) 10^{3} / \mu \mathrm{L}$ & $\mathbf{1 . 3 7} \uparrow$ & $0.06-1.23$ \\
\hline Baso. & $(\%) 10^{3} / \mu \mathrm{L}$ & 0.08 & $0.00-0.10$ \\
\hline Lymph. & $(\%) 10^{3} / \mu \mathrm{L}$ & $\mathbf{7 . 0 6} \uparrow$ & $1.05-5.10$ \\
\hline Mono. & $(\%) 10^{3} / \mu \mathrm{L}$ & $\mathbf{1 . 7 2} \uparrow$ & $0.16-1.12$ \\
\hline PLT & $10^{3} / \mu \mathrm{L}$ & 202 & $148-484$ \\
\hline
\end{tabular}

a: Full name of test subjects: RBC, red blood cell; HCT, haematocrit; HGB, haemoglobin; $\mathrm{MCV}$, mean corpuscular volume; $\mathrm{MCH}$, mean corpuscular haemoglobin; $\mathrm{MCHC}$, mean corpuscular haemoglobin concentration; WBC, white blood cell; Neu., neutrophil; Lymph., lymphocyte; Mono., monocyte; Eosino., eosinophil; Baso., basophil; PLT, platelet

b: Reference range from: IDEXX ProCyte Dx ${ }^{\circledR}$ Hematology Analyzer (IDEXX Laboratories, Inc., Westbrook, ME USA). 
Table 2: Serum biochemical examination

\begin{tabular}{|l|l|l|l|}
\hline Test a & \multicolumn{1}{|c|}{ Unit } & Result & Reference Interval \\
\hline GLU & $\mathrm{mg} / \mathrm{dL}$ & 115 & $70-143^{\mathrm{b}}$ \\
\hline BUN & $\mathrm{mg} / \mathrm{dL}$ & 12 & $7-27^{\mathrm{b}}$ \\
\hline CREA & $\mathrm{mg} / \mathrm{dL}$ & 0.8 & $0.5-1.8^{\mathrm{b}}$ \\
\hline PHOS & $\mathrm{mg} / \mathrm{dL}$ & 3.6 & $2.5-6.8^{\mathrm{b}}$ \\
\hline CA & $\mathrm{mg} / \mathrm{dL}$ & 10.5 & $7.9-12.0^{\mathrm{b}}$ \\
\hline TP & $\mathrm{g} / \mathrm{dL}$ & $\mathbf{8 . 9} \uparrow$ & $5.2-8.2^{\mathrm{b}}$ \\
\hline ALB & $\mathrm{g} / \mathrm{dL}$ & 3.0 & $2.2-3.9^{\mathrm{b}}$ \\
\hline GLOB & $\mathrm{g} / \mathrm{dL}$ & $\mathbf{5 . 9} \uparrow$ & $2.5-4.5^{\mathrm{b}}$ \\
\hline ALT & $\mathrm{U} / \mathrm{L}$ & 51 & $10-125^{\mathrm{b}}$ \\
\hline ALKP & $\mathrm{U} / \mathrm{L}$ & 71 & $23-212^{\mathrm{b}}$ \\
\hline GGT & $\mathrm{U} / \mathrm{L}$ & 0 & $0-11^{\mathrm{b}}$ \\
\hline TBIL & $\mathrm{mg} / \mathrm{dL}$ & 0.7 & $0.0-0.9^{\mathrm{b}}$ \\
\hline CHOL & $\mathrm{mg} / \mathrm{dL}$ & 151 & $110-320^{\mathrm{b}}$ \\
\hline Na & $\mathrm{mmol} / \mathrm{L}$ & 157 & $144-160^{\mathrm{c}}$ \\
\hline $\mathrm{K}^{+}$ & $\mathrm{mmol} / \mathrm{L}$ & 4.5 & $3.5-5.8^{\mathrm{c}}$ \\
\hline Cl- & $\mathrm{mmol} / \mathrm{L}$ & 117 & $109-122^{\mathrm{c}}$ \\
\hline
\end{tabular}

a: Full name of test subjects: GLU, glucose; BUN, blood urea nitrogen; CREA, creatinine; PHOS, phosphate; CA, Calcium ion; TP, total protein; ALB, albumin; GLOB, globumin; ALT, alanine aminotransferase; ALKP, alkaline phosphatase; GGT, Gamma-glutamyl transferase; TBIL, total bilirubin; $\mathrm{CHOL}$, cholesterol; $\mathrm{Na}^{+}$, Sodium ion; $\mathrm{K}^{+}$, Potassium ion; $\mathrm{Cl}$, Chloride ion

b: Reference range from SPOTCHEM ${ }^{\mathrm{TM}}$ SP-4430 dry biochemical analyzer (Arkray, Kyoto, Japan).

c: Reference range from SPOTCHEM ${ }^{\mathrm{TM}}$ EL SE-1520 electrolyte analyzer (Arkray, Kyoto, Japan)

On the advice of veterinarians, the owner agreed to remove the mass through surgery. The mass was surgically removed through a full-thickness V-excision. A figure-of-eight suture was applied to the edge of the eyelid to separate the knot from the edge of the eyelid. A simple interrupted suture was used to close the remaining wound away from the edge of the eyelid. The mass was pink, cauliflower-like, and hairless.

For histopathological examinations, the mass was fixed in $10 \%$ neutral buffered formalin for 24 hours. After tissue dehydration, paraffin embedding, and slicing to make sections, tissue sections were stained with haematoxylin and eosin (Figure 1).

\section{Discussion}

This particular fibrosarcomas was well-demarcated and nonencapsulated. The visible tumour cells have scant cytoplasm and oval to spindle-shaped nuclei with inconspicuous nucleoli. Cells are spindle shaped and arranged in interwoven patterns [4]. In other field, numerous mitotic figures are observed, and cells have marked cellular and nuclear pleomorphisms [13]. Bright pink collagenous stroma, which are produced by fibroblasts, can be observed between the neoplastic cells.
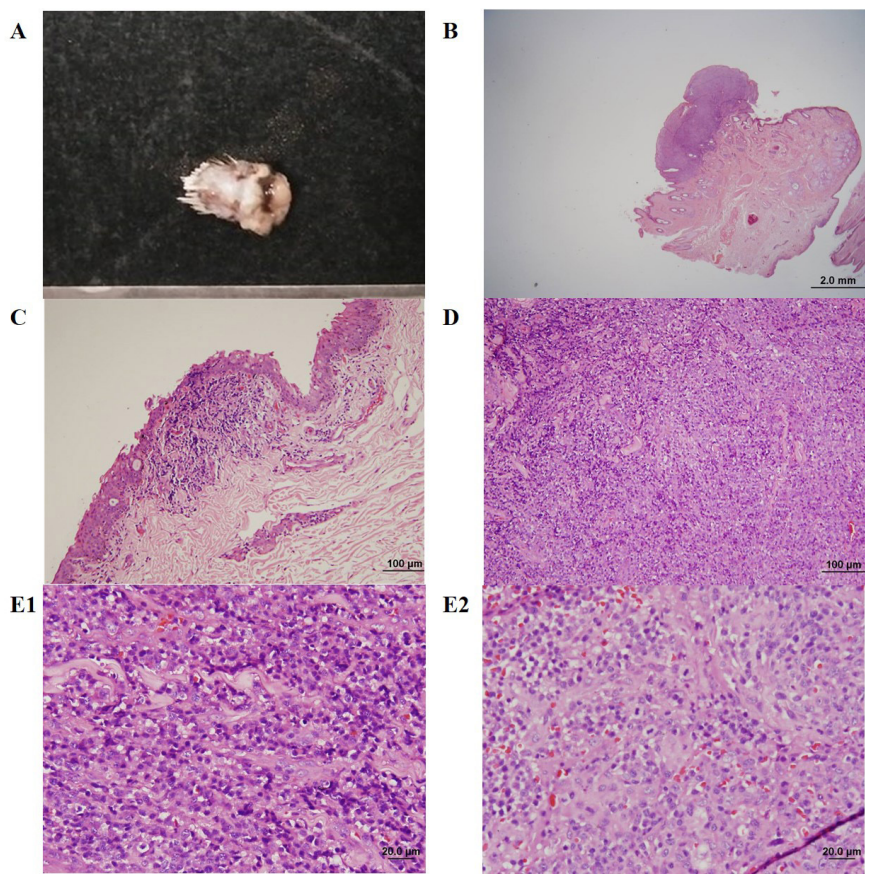

Figure 1.

Within the field of veterinary medicine, the treatment of STSs includes surgery, chemotherapy, radiation therapy (RT), and combination therapies [9]. The main treatment for sarcomas is surgical resection [18]. For surgical resection, the recommended excision width for STSs is $30 \mathrm{~mm}$ lateral to the tumour and one fascial plane $[6,12]$. For marginal surgical resection, the excision is made just outside the tumour or at the pseudocapsule [18]. In the current case, the resection was made with a margin of only $1 \mathrm{~cm}$ from the tumour. In this situation, marginal resection should be combined with other therapies. RT is used with marginal resection to obtain local control equivalent to radical resection alone [14]. RT should begin 10 to 14 days postoperatively to minimize the risk of the dehiscence or infection of the surgical wound [15]. The efficacy of chemotherapy for controlling soft tissue sarcoma among dogs remains unknown, and it is only recommended for tumours with high histologic grades $[3,9,14]$.

The predictors of outcome related to STSs include size, location, grade, histologic type, previous treatment, and surgical margins. Tumour size and location may be prognostic only through their effect on the completeness of the margins [6]. Histological grade is regarded as a more reliable predictor of outcome [1]. Criteria regarding histological grade are detailed by Lipta \& Forrest [12]; the American Joint Committee on Cancer staging system was modified from the human STSs staging system. The current case was classified as histologic grade I-II (T1aN0M0; Suppl. 1). Management of low-grade (grade I, grade II) STSs with marginal resection includes frequent monitoring for local recurrence and the appropriate treatment for tumour recurrence [12].

The metastatic rate for soft tissue sarcoma is less than $20 \%$. However, for high-grade tumours, the metastatic rate is estimated as 
$50 \%$ [7]. During the late course of the disease local metastasis often occurs, with a median time of approximately 384 days [8]. Overall, the mean survival time (MST) for dogs with STSs was reported as 1416 days for those treated with surgery alone [11]. By contrast, the MST for fibrosarcomas and hemangiopericytomas was 1851 days, and dogs treated with postoperative RT had an MST of 2270 days [9].

Supplementary material

Suppl. Table 1 Modified Staging System for Canine Soft Tissue Sarcomas (Lipta \& Forrest 2013).

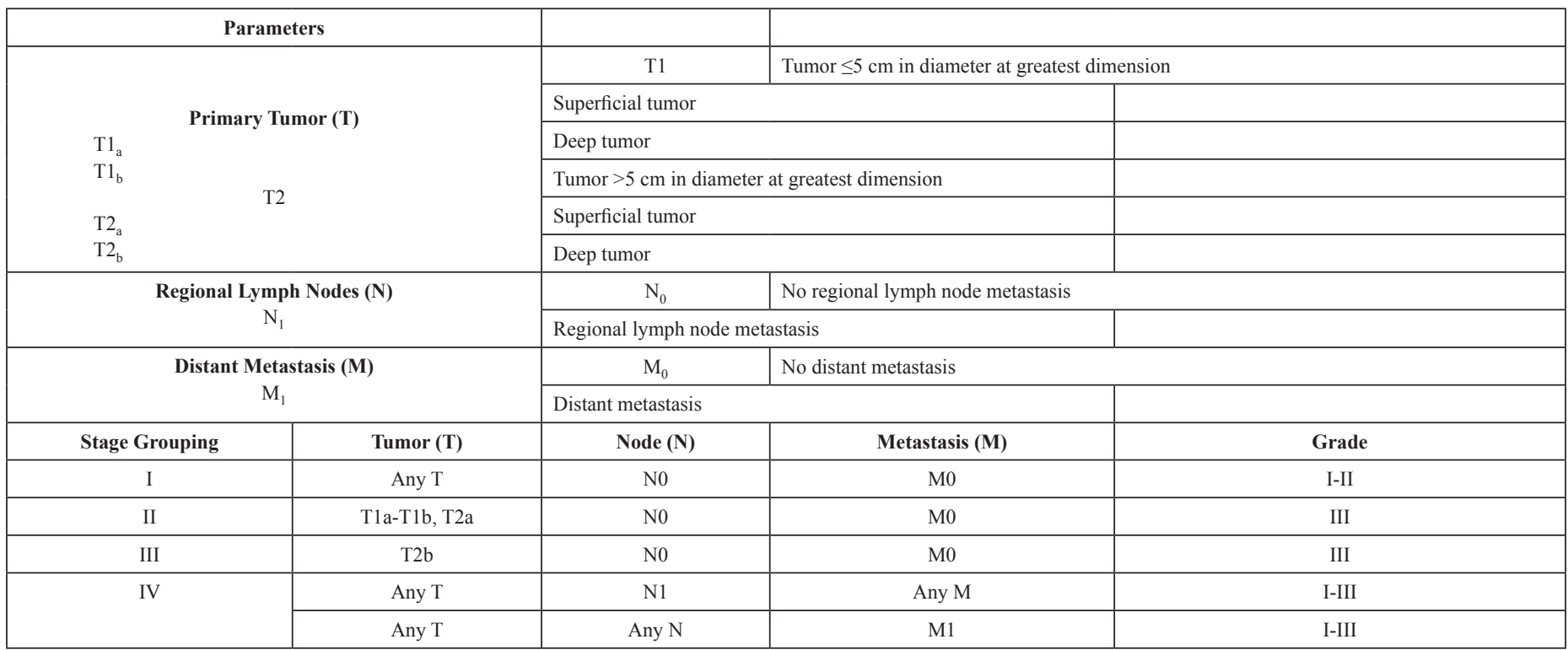

\section{Acknowledgements}

The authors thank Jing-Rong $\mathrm{Hu}$ of the Department of Veterinary Medicine, National Chiayi University for conducting the histopathological examination.

\section{Conflict of interest}

None of the authors of this article has a financial or personal relationship with other people or organisations that could inappropriately influence or bias the content of the paper.

\section{References}

1. Baker-Gabb M, Hunt GB, France MP (2003) Soft tissue sarcomas and mast cell tumours in dogs; clinical behaviour and response to surgery. Aust Vet J 81: 732-738. [crossref]

2. Bedrossian CW, Verani R, Unger KM, Salman J (1979) Pulmonary malignant fibrous histiocytoma. Light and electron microscopic studies of one case. Chest 75: 186-189.

3. Casper ES, Gaynor JJ, Harrison LB, Panicek DM, Hajdu SI, Brennan MF (1994) Preoperative and postoperative adjuvant combination chemotherapy for adults with high grade soft tissue sarcoma. Cancer 73: 1644-165.

4. Crago AM, Brennan MF2 (2015) Principles in Management of Soft Tissue Sarcoma. Adv Surg 49: 107-122. [crossref]

5. Dennis MM, McSporran KD, Bacon NJ, Schulman FY, Foster RA, et al. (2011) Prognostic factors for cutaneous and subcutaneous soft tissue sarcomas in dogs. Vet Pathol 48: 73-84. [crossref]

6. Dernell WS, Withrow SJ, Kuntz CA, Powers BE (1998) Principles of treatment for soft tissue sarcoma. Clin Tech Small Anim Pract 13: 59-64. [crossref]

7. Ehrhart N (2005) Soft-tissue sarcomas in dogs: a review. J Am Anim Hosp Assoc 41: 241-246. [crossref]

8. Fong Y, Coit DG, Woodruff JM, Brennan MF (1993) Lymph node metastasis from soft tissue sarcoma in adults. Analysis of data from a prospective database of 1772 sarcoma patients. Ann Surg 217: 72-77.
9. Forrest LJ, Chun R, Adams WM, Cooley AJ, Vail DM (2000) Postoperative radiotherapy for canine soft tissue sarcoma. J Vet Intern Med 14: 578-582. [crossref]

10. Krohel GB, Rosenberg PN, Wright JE, Smith RS (1985) Localized orbital neurofibromas. Am J Ophthalmol 100: 458-464. [crossref]

11. Kuntz CA, Dernell WS, Powers BE, Devitt C, Straw RC, Withrow SJ (1997) Prognostic factors for surgical treatment of soft-tissue sarcomas in dogs: 75 cases (1986-1996). J Am Vet Med Assoc 211: 1147-115.

12. Lipta JM, Forrest LJ (2012) Soft tissue sarcomas. In: Withrow, SJ and Vail, DM (Eds.), Small animal clinical oncology, 5th ed. Elsevier Medicine Press, Philadelphia, 356-380.

13. Madarame H, Sato K, Ogihara K, Ishibashi T, Fujii Y, et al. (2004) Primary cardiac fibrosarcoma in a dog. J Vet Med Sci 66: 979-982. [crossref]

14. McKnight JA, Mauldin GN, McEntee MC, Meleo KA, Patnaik AK (2000) Radiation treatment for incompletely resected soft-tissue sarcomas in dogs. $J \mathrm{Am}$ Vet Med Assoc 217: 205-210. [crossref]

15. McLeod DA, Thrall DE (1989) The combination of surgery and radiation in the treatment of cancer. A review. Vet Surg 18: 1-6. [crossref]

16. Nakajima T, Watanabe S, Sato Y, Kameya T, Hirota T, Shimosato Y (1982) An immunoperoxidase study of S-100 protein distribution in normal and neoplastic tissues. Am J Surg Pathol 6: 715-727.

17. Roncaroli F, Eusebi V (1996) Rhabdomyoblastic differentiation in a leiomyosarcoma of the retroperitoneum. Hum Pathol 27: 310-313. [crossref]

18. Stefanello D, Morello E, Roccabianca P, Iussich S, Nassuato C, et al. (2008) Marginal excision of low-grade spindle cell sarcoma of canine extremities: 35 dogs (1996-2006). Vet Surg 37: 461-465.

19. Theilen GH, Madwell BR (1979) Tumours of the skin and subcutaneous tissues. In: Veterinary cancer medicine, 2nd ed. Lea and Febiger, Philadelphia, 123-19.

Citation:

I-Hsuan Teng, Ming-Wei Lee, Chun-Fu Lin, Geng-Ruei Chang (2017) Fibrosarcoma of the Lower Eyelid in a Dog. Integr J Vet Biosci Volume 1(1): 1-3 